\title{
Stress Corrosion Cracking of 4340 Steel in Different Environments*
}

\author{
By Noriyoshi TANIGUCHI ${ }^{* *}$ and A.R. TROIANO***
}

\section{Synopsis}

Stress corrosion cracking of 4340 steel in various environments was examined in terms of delayed failure using round bar, precracked, specimens at $190 \mathrm{~kg} / \mathrm{mm}^{2}$ strength level. Current fracture toughness testing techniques were employed for the analysis. Hydrogen embrittlement was employed as the precracking method and this was considered to have the advantage of minimizing plastic deformation in comparison to the conventional fatigue cracking method.

Two dilute $\mathrm{NaCl}$ aqueous solutions and distilled water caused extreme susceptibility to delayed failure. Two organic solutions, butyl alcohol and acetone, also induced a milder form of delayed failure. Possible mechanisms for the stress corrosion cracking were discussed.

The use of precracked specimens in evaluating stress corrosion cracking phenomenon was established as an effective testing technique.

\section{Introduction}

Many problems associated with stress corrosion cracking phenomena have been observed in the use of alloy steels heat-treated to high strength levels. One of the main problems in working with this phenomena is that it is difficult to reproduce in a laboratory because of the complexities involved. Mechanisms which produce this behavior are considered to be different for each situation and there has been no consistent interpretation. Evaluation of the laboratory results and applying them to actual design situation are also difficult.

Recently, a testing method using precracked specimens has been reported. ${ }^{1)}$ The use of such specimens makes it possible to get a significant evaluation of the susceptibility of a material to stress corrosion cracking. In other words, the test has the advantages of being able to shorten the testing time by eliminating pitting process and also being able to test for stress corrosion cracking in alloys which do not pit but are susceptible.

Another important advantage of this test is the applicability of linear elastic fracture mechanics concepts (fracture toughness $)^{5), 6)}$ to the analysis of results, and several investigations of stress corrosion cracking tests which have used this concept have been reported. ${ }^{1)-4}$ )

The basic idea of stress corrosion cracking testing with the aid of fracture toughness analysis is believed to be related to the behavior that stress corrosion cracking may initiate below $K_{I c}$ involving an environmentally induced cracking process, eventually causing delayed failure. It has been suggested that there might be a certain value designated as stress corrosion cracking stress intensity factor $K_{I s c c}$ below which delayed failure does not occur. ${ }^{1)}$

Precracking is usually performed by fatigue method.
However, a hydrogen delayed failure mechanism ${ }^{7)}$ might be employed for the formation of the precrack at the root of the notch. The precracking technique by hydrogen embrittlement eliminates the possibility of localized plastic deformation that occurs in mechanical fatigue method. Therefore, there might be an advantage in the use of hydrogen precracked specimens particularly when determining the $K_{I s c e}$ values, because it is well established that plastic deformation will tend to make the metal more anodic and thus set the stage for increased corrosion.

The characteristic behavior of hydrogen to produce delayed failure as a part of hydrogen embrittlement in high strength steel materials has been observed and extensively studied. ${ }^{7), 9)}$ The delayed failure investigations are performed by testing electrolytically hydrogenated notched speimens at a fixed tensile load and recording the time to failure. The typical delayed failure curve is illustrated in Fig. 1. Thus, utilizing the above characteristics, any required crack size for the fracture toughness testing of high tensile steels would be obtained by controlling the amount of hydrogen, stress level, and loading time. This paper reports the results of the possibility of application of hydrogen delayed failure concepts to produce an appropriate precracked specimen for the purpose of fracture toughness testing of high tensile strength martensitic steel and the investigation of $K_{I s e c}$ values in several environments including organic solutions.

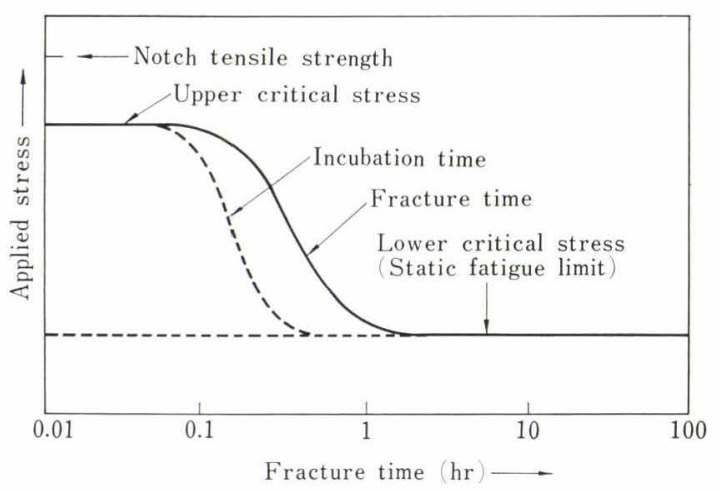

Fig. 1. Schematic representation of static fatigue characteristics of a hydrogenated high strength steel ${ }^{7}$

\section{Materials and Procedure}

\section{Specimen Preparation}

Aircraft quality SAE-AISI 4340 steel of the follow-

* This paper is based on a thesis submitted in June, 1968, by N. Taniguchi to the Department of Metallurgy, Case Western Reserve University in partial fulfillment of the requirements for the M.S. degree in Metallurgy. Received November 1, 1968.

** Research Associate, Central Research Laboratories of Fuji Iron \& Steel Co., Ltd., Fuchinobe, Sagamihara 229.

*** Department of Metallurgy, Gase Western Reserve University, Gleveland, Ohio, U.S.A. 
ing chemical analysis (Table 1) was used for the investigation.

Table 1. Composition of 4340 steel (wt \%)

\begin{tabular}{cccccccc}
\hline $\mathrm{C}$ & $\mathrm{Mn}$ & $\mathrm{Si}$ & $\mathrm{P}$ & $\mathrm{S}$ & $\mathrm{Ni}$ & $\mathrm{Cr}$ & $\mathrm{Mo}$ \\
\hline 0.41 & 0.84 & 0.30 & 0.013 & 0.020 & 1.73 & 0.83 & 0.20 \\
\hline
\end{tabular}

The above material was furnished in the form of 15.9 $\mathrm{mm}$ dia. hot-rolled bars.

Studies were initially performed on specimens heattreated to two different strength levels, 160 and 190 $\mathrm{kg} / \mathrm{mm}^{2}$ respectively. However, the main study of stress corrosion was centered on $190 \mathrm{~kg} / \mathrm{mm}^{2}$ strength level because of the results of size requirements for valid fracture toughness testing. Test specimens taken from the above bars were heat-treated according to the following schedule :

(1) Rough machine specimen blanks (no notch) $0.5 \mathrm{~mm}$ oversize.

(2) Austenitize blanks at $842^{\circ} \mathrm{C}$ for one hour in a salt bath and oil quench.

(3) Temper for $30 \mathrm{~min}$ at $371^{\circ} \mathrm{C}$ to obtain 160 $\mathrm{kg} / \mathrm{mm}^{2}$ strength level or for $30 \mathrm{~min}$ at $232^{\circ} \mathrm{C}$ to obtain $190 \mathrm{~kg} / \mathrm{mm}^{2}$ strength level.

(4) Finish machine.

Test specimens with various shank diameters and tensile specimens were employed for the experiments and the dimensions are shown in Fig. 2.

\section{Application of Fracture Toughness Testing Techniques}

Proper specimen dimensions for measuring fracture toughness and evaluating subsequent stress corrosion cracking tests are important to note because valid plane strain conditions must exist to avoid misleading data. Therefore, a preliminary investigation was conducted to determine the appropriate specimen sizes by examining the influence of specimen size on critical stress intensity factor and notch tensile ratio. The brief results are depicted in Fig. 3. From the results of this preliminary test, the specimen sizes for the stress corrosion testing were decided to be 7.62 and $11.43 \mathrm{~mm}$ shank diameters at $190 \mathrm{~kg} / \mathrm{mm}^{2}$ strength level.

The stress intensity factors in the circumferentially notched specimen tests were computed from Bueckner's (6) equations,

$$
\begin{gathered}
K_{I}=Y \cdot \frac{P}{D^{3 / 2}} \\
Y=3.543\left(1.72_{d}^{D}-1.27\right)
\end{gathered}
$$

where,

$K_{I}$ : plane strain stress intensity factor $\left(\mathrm{kg} \sqrt{\mathrm{mm} / \mathrm{mm}^{2}}\right)$

$D$ : shank diameter $(\mathrm{mm})$

$d$ : diameter at the crack, measured after testing $(\mathrm{mm})$

$P$ : applied load $(\mathrm{kg})$

$Y: K$ calibration factor.

The equations are applicable in the range of diameter ratio $d / D$ between 0.5 and $0.8 .^{6)}$ As for the notch size and crack depth relation, specimens were initially notched to yield a $d / D$ ratio of 0.75 and the final $d / D$ ratio (based on the crack circle diameter) was controlled to be within 0.707 and $0.650{ }^{81}$

\section{Hydrogen Charging and Precracking}

Resistance measurements were employed to control the crack depth precisely using $D=7.62 \mathrm{~mm}$ specimens. A calibration curve which indicates a relation between the relative resistance increase and cross-sectional area

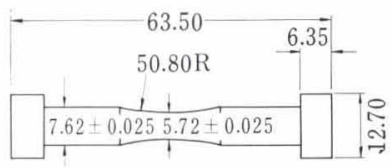

Unnotched tensile specimen

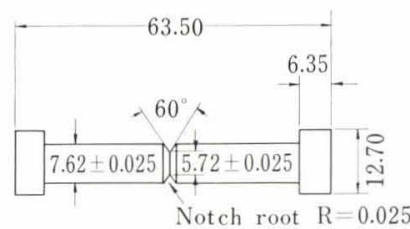

$D=7.62 \mathrm{~mm}$ notched specimen

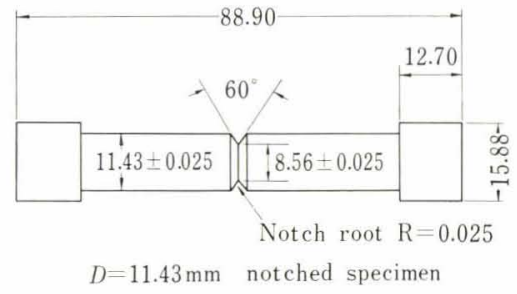

Fig. 2. Specimen types employed in this investigation
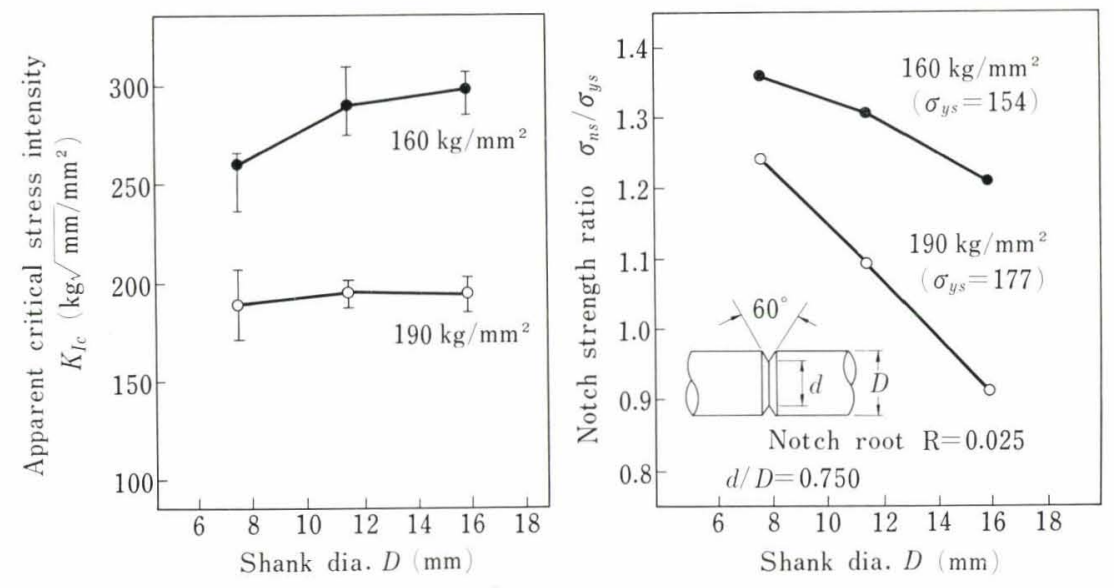

Fig. 3.

Effect of specimen size on measured $K_{I c}$ value and notch strength ratio of 4340 steel at two strength levels 
is illustrated in Fig. 4.10) The loading time for all specimens was determined from the above data. Briefly, the procedures were as follows. An electrolytic hydrogen charging technique was used. Specimens were degreased in acetone and then cathodically charged for five minutes in a $4 \%$ sulfuric acid solution. A current density of $1.5 \mathrm{~mA}$ per square $\mathrm{cm}$ gave an adequate crack size. Immediately after the charging the specimens were washed in water and dried carefully but swiftly especially around the notch. Specimens were next submitted to a constant load test at a certain stress level for precracking to obtain an appropriate crack size. The stress level and loading time of 84.4 $\mathrm{kg} / \mathrm{mm}^{2}$ stress level for approximately five minutes gave a proper crack depth for all specimen sizes.

The time interval between the end of hydrogen charging and the initiation of constant loading was maintained within five minutes.

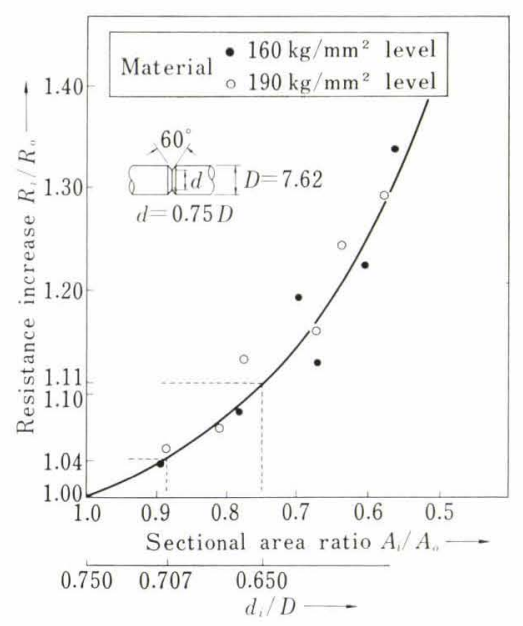

Fig. 4. Normalized calibration curve, resistance vs. crosssectional area for 4340 steel at $84.4 \mathrm{~kg} / \mathrm{mm}^{2}$ stress level

\section{Testing Methods}

Tensile tests and two delayed failure tests were conducted. The two delayed failure tests were induced by hydrogen embrittlement and also induced environmentally, but the principal investigation was focused on the latter test. All three tests were performed with centrally aligned fixtures which insured an eccentricity of less than $0.025 \mathrm{~mm}$ in uniaxial loading. The tensile tests for the conventional material evaluation and fracture toughness testing were performed at a constant crosshead speed of $1.3 \mathrm{~mm}$ per minute. The static loading test for precracking by hydrogen and the delayed failure tests were conducted on constant load, lever arm, stress rupture machines. After static loading for precracking, specimens were baked and tinted at $204^{\circ} \mathrm{C}$ for one hour in order to distinguish the precracked area from the fresh crack and to remove electrically charged hydrogen.*

All tests were performed at room temperature and the maximum test time for the delayed failure investigations was $100 \mathrm{hr}$. The fractured surface of the speci- mens were carefully examined through a stereotype microscope. A magnification of X10 or X20 was used to measure the precracked depth, the slow cracked portion, and rapid cracked section.

\section{Environments for Stress Corrosion Testing}

The following solutions were chosen in this investigation for the test:

(1) $4 \% \mathrm{NaCl}$ aqueous solution

(2) $2 \% \mathrm{NaCl}$ aqueous solution

(3) distilled water

(4) butyl alcohol

(5) acetone.

The precracked portion of the specimen was submerged in the solution held by a closed plastic container. In the testing order, the solution was applied to the specimen immediately after application of the load.

\section{Result and Discussion}

\section{Material Properties}

Conventional tensile tests were conducted on the 4340 steel, heat treated to the indicated strength levels, using the specimen illustrated in Fig. 2. The results are summarized in Table 2 .

Table 2. Mechanical test results

\begin{tabular}{l|r|r}
\hline & \multicolumn{2}{|c}{ Strength level } \\
\hline Nominal strength level $\left(\mathrm{kg} / \mathrm{mm}^{2}\right)$ & 160.0 & 190.0 \\
Tensile strength $\left(\mathrm{kg} / \mathrm{mm}^{2}\right)$ & 165.9 & 205.7 \\
Yield strength $\left(\mathrm{kg} / \mathrm{mm}^{2}\right)(0.2 \%$ offset $)$ & 153.9 & 177.4 \\
Reduction in area $(\%)$ & 43.8 & 36.4 \\
Fracture strength $\left(\mathrm{kg} / \mathrm{mm}^{2}\right)$ & 225.1 & 276.5 \\
\hline
\end{tabular}

\section{Fracture Toughness by Hydrogen Precracking}

A comparison of the two methods on the actual fracture toughness value was attempted. Most of the test data for 4340 steel now available has been obtained with plate specimens and it has not been possible to find data in the literature for round bar specimens. The $K_{I c}$ value determined in this investigation is in good agreement with the other data on 4340 steel. ${ }^{11)}$ However, a more precise comparison of the effects of the two techniques should be made in the light of the following points:

(1) The fracture toughness values scatter more as the strength level increases, therefore lower strength levels should be chosen for the comparison. Also the lower strength material would give a larger plastic zone at the crack tip.

(2) The same specimen geometry should be selected to avoid the configurational effects.

Thus, further investigations would be required to evaluate the effects of different precracking techniques on fracture toughness.

\section{Stress Corrosion Delayed Failure Testing}

\section{General Feature of Delayed Failure}

Delayed failure curves, as a criterion of stress corro-

* This treatment is used commercially to attain complete recovery from the effects of hydrogen and proved to be most effective here. 
sion, were obtained for the five solutions using 7.62 and $11.43 \mathrm{~mm}$ shank diameter precracked 4340 specimens at $190 \mathrm{~kg} / \mathrm{mm}^{2}$ strength level. These are illustrated in Figs. 5 through 9. The curves are presented with applied initial stress intensity $K_{I i}$, as determined from the load and the initial precracked diameter in the plane of the notch, indicated along the ordinate, and with the logarithm of the time to failure on the abscissa. The applied stress intensity depicted at zero time corresponds to critical stress intensity factor $K_{I c}$, obtained in the fracture toughness testing conducted in air.

Figures 5 to 7 indicate that all of the aqueous solutions $(4 \% \mathrm{NaCl}, 2 \% \mathrm{NaCl}$, and distilled water) produced delayed failures over a wide range of $K_{I}$ values for both diameter specimens. Another remarkable point of the results is that these curves dropped off at a relatively rapid rate in the presence of these liquid environments. In other words, the fracture toughness was drastically reduced from $194.9 \mathrm{~kg} \sqrt{\mathrm{mm}} / \mathrm{mm}^{2}$ in air to less than $70.9 \mathrm{~kg} \sqrt{\mathrm{mm} / \mathrm{mm}^{2}}$ within $10 \mathrm{~min}$. Steigerwald, et al. ${ }^{12)}$ and Brown, et al. ${ }^{4)}$ have reported similar experimental results with $\mathrm{NaCl}$ aqueous solutions and distilled water using different specimen geometries such as center notched plate specimens and cantilever beam specimens. The results of this investigation agree well with the above data. This would indicate consistency of the stress corrosion delayed failure characteristics in terms of linear elastic fracture mechanics. The aqueous solution environments resulted in a shift in delayed failure times for the different specimen diameters, the larger specimens requiring slightly longer times to fail than the smaller ones. Although the rate of slow crack propagation was not studied, this variation in failure time might be understood by considering the different distance for crack growth. Assuming that the crack propagates at the same velocity for a certain $K_{I}$ level in specimens of different size, the larger specimen would require a longer time to reach the same $d_{f} / d_{o}$ ratio (see Photo. 1 for $d_{f}$ and $d_{o}$ ).

On the other hand, the results of Figs. 8 and 9, which were obtained in butyl alcohol and acetone environments, disclosed that those liquids, especially acetone, induced rather narrow delayed failure ranges. Also the times to failure were significantly longer than

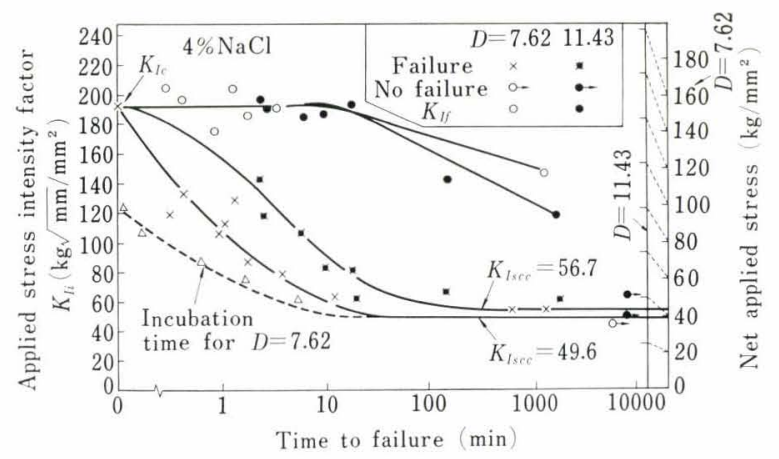

Fig. 5. Delayed failure curves of 4340 steel in $4 \% \mathrm{NaCl}$ solution at $190 \mathrm{~kg} / \mathrm{mm}^{2}$ strength level for the aqueous solutions. However, it is noteworthy that these common organic solutions, which are generally considered to be inactive or anticaustic with respect to steel, could even produce delayed failure.

The $K_{I s c c}$ values, which are defined as stress corrosion cracking stress intensity below which delayed failure does not occur, were determined for the various solutions and two specimen diameters. These $K_{I s c c}$ values are summarized in Table 3 .

$K_{\text {Iscc }}$ values as obtained on different specimen sizes or configurations should be the same in any one en-

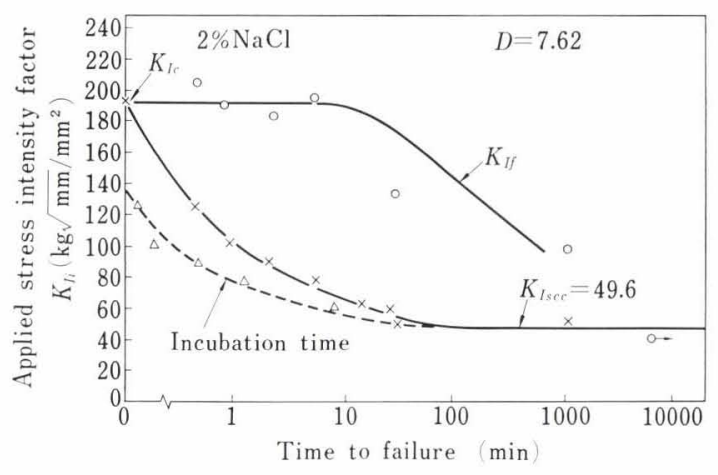

Fig. 6. Delayed failure curve of 4340 steel in $2 \% \mathrm{NaCl}$ solution at $190 \mathrm{~kg} / \mathrm{mm}^{2}$ strength level

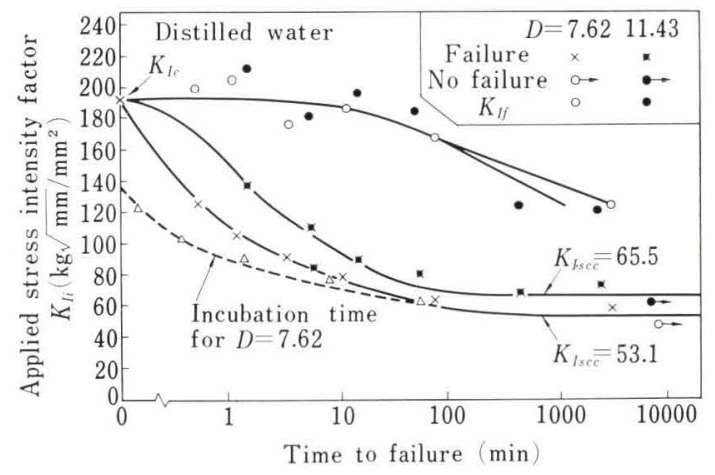

Fig. 7. Delayed failure curves of 4340 steel in distilled water at $190 \mathrm{~kg} / \mathrm{mm}^{2}$ strength level

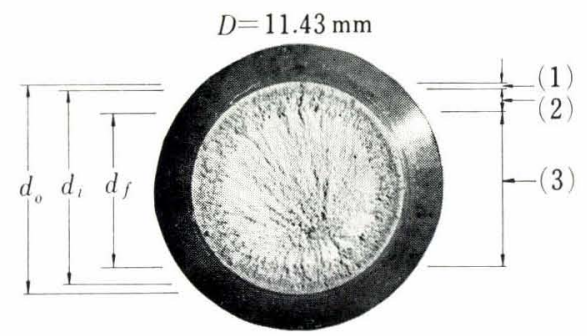

(1) Precrack by hydrogen (heat tinted)

(2) Slow crack propagation, environmentally induced

(3) Rapid fracture

$4 \% \mathrm{NaCl}$ aq. environment

$K_{I i}=166.5 \mathrm{~kg} \sqrt{\mathrm{mm} / \mathrm{mm}^{2}}$

$K_{I f}=203.0 \mathrm{~kg} \sqrt{\mathrm{mm} / \mathrm{mm}^{2}}$

Photo. 1. Fracture appearance of 4340 round bar specimen, $190 \mathrm{~kg} / \mathrm{mm}^{2}$ strength level 
vironment. However, it has been observed by several investigators ${ }^{4), 13)}$ that there is a difference in environmental effect upon the stress corrosion susceptibility with the different specimen geometries. Within a limit of experimental error, the two specimen sizes in Table 3 produced essentially the same values for a given environment.

The typical fractured surface appearance of $11.43 \mathrm{~mm}$ dia. specimen is presented in Photo. 1. The fractured surface delineates three regions from periphery to center (1) the precracked zone, (2) the region of slow crack propagation by stress corrosion cracking, and (3) the section of rapid propagation. The region of slow crack propagation and stress corrosion is rougher than that for catastrophic failure.

\section{$\boldsymbol{K}_{I f}$ Values From Final Cross-Sectional Area}

Two stress intensity factors can be calculated from the fractured surface of the specimens as illustrated in

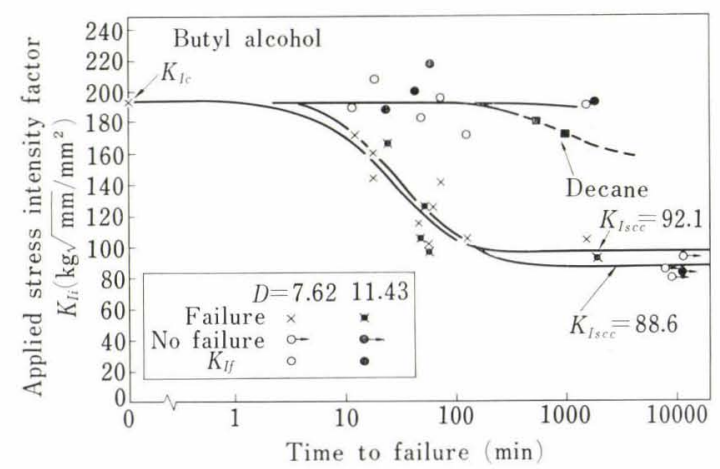

Fig. 8. Delayed failure curves of 4340 steel in butyl alcohol at $190 \mathrm{~kg} / \mathrm{mm}^{2}$ strength level

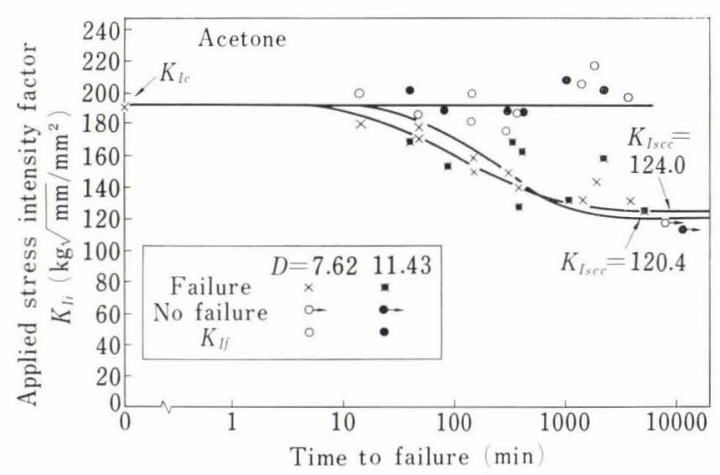

Fig. 9. Delayed failure curves of 4340 steel in acetone at $190 \mathrm{~kg} / \mathrm{mm}^{2}$ strength level

Table 3. $k_{\text {Iscc }}\left(\mathrm{kg} \sqrt{\mathrm{mm}} / \mathrm{mm}^{2}\right)$ values for the solutions

\begin{tabular}{l|r|c}
\hline \multicolumn{1}{c|}{ Solution } & $7.62 \mathrm{~mm} \mathrm{dia.}$ & $11.43 \mathrm{~mm}$ dia. \\
\hline $4 \% \mathrm{NaCl}$ aq. solution & 49.6 & 56.7 \\
$2 \% \mathrm{NaCl}$ aq. solution & 49.6 & - \\
Distilled water & 53.1 & 65.5 \\
Butyl alcohol & 92.1 & 88.6 \\
Acetone & 124.0 & 120.4 \\
\hline
\end{tabular}

Photo. 1: (1) a $K_{I i}$ value, using a constant load and $d_{i}$, which is the diameter at the root of the precrack and (2) a $K_{I f}$ using the same load and $d_{f}$, which is the diameter of the area of rapid fracture.

The embrittlement process occurs simply at the tip of the crack and an external environment does not alter the bulk intrinsic material toughness. ${ }^{13), 17)}$ The material fractures when the slowly propagated crack reaches a certain critical size for the applied load. On the basis of the above considerations, the $K_{I f}$ values must correspond with the $K_{I c}$ value of the material.

The $K_{I f}$ values were computed for each testing situation in order to examine the relation between the $K_{I c}$ value and the $K_{I f}$ values. The results are presented in Figs. 5 to 9 . The curves indicate that in most of the tests the $K_{I f}$ values agree with the $K_{I c}$ value over a relatively wide scattered band. However, the apparent $K_{I f}$ values deviate appreciably from the $K_{I c}$ values as the applied initial stress intensities are lowered. For these situations, Bueckner's equations for round notched bar specimens are not applicable for the computation of $K_{I}$ values because the $d_{f}$ values fall below the required range of $d / D=0.5$ to 0.8 .

\section{Stress Corrosion Mechanism}

The environmentally induced failure of high strength steels under constant load can be caused by one or more of the following mechanisms: (a) Hydrogen embrittlement (b) Stress sorption cracking. Hanna, Steigerwald, and Troiano ${ }^{14)}$ have reported a series of experiments which included studies of incubation periods for crack initiation and its reversibility. They indicated that the delayed failure of martensitic highstrength steel in distilled water or in moist air environments was due to a hydrogen embrittlement mechanism where the nascent hydrogen is produced by the corrosion reaction. ${ }^{14)}$

Resistance measurements were employed to examine the crack incubation time in $\mathrm{NaCl}$ aqueous solutions and distilled water, using $7.62 \mathrm{~mm}$ dia. specimens. Typical crack propagation characteristics in a $4 \%$ $\mathrm{NaCl}$ aqueous environment at $63.8 \mathrm{~kg} \sqrt{\mathrm{mm}} / \mathrm{mm}^{2}$ level are presented in Fig. 10. The result indicates that an incubation time was required before slow crack growth was initiated. The influence of applied initial stress intensity on the incubation time is illustrated in Figs. 5 to 7 , as a dotted line. These figures indicate that an incubation period exists below a certain stress intensity level in the $\mathrm{NaCl}$ environments and in distilled water. This behavior is consistent with embrittlement by hydrogen supplied by the corrosion reaction.

In the case of butyl alcohol and acetone, the existence of a source of hydrogen appears to be more difficult to explain on the assumption that the delayed failure is caused by hydrogen embrittlement. Hydrogen can be attributed to one or both of two sources: (1) existence of water in the solutions, (these liquids are hydroscopic) (2) hydrogen from dissociation of the environmental solutions at the apex of the crack. However, source (2) does not seem reasonable when considering the nature of the chemical properties of the solutions. ${ }^{16)}$ Therefore, the cause of delayed failure 


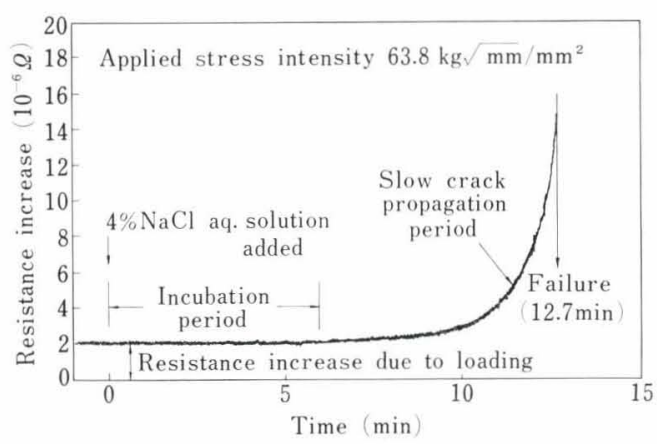

Fig. 10. Crack initiation and propagation of 4340 steel at $190 \mathrm{~kg} / \mathrm{mm}^{2}$ strength level in $4 \% \mathrm{NaCl}$ aq. solution. $D=7.62 \mathrm{~mm}$ precracked specimen

and the difference of susceptibility on the basis of hydrogen embrittlement would be due to the difference of the water content of the solutions. These two solutions do have appreciable solubility for water.

On the other hand, the mechanism called stress sorption cracking claims that the delayed failure is, at least in part, due to the reduction of the surface of bonding energy of the metal at the tip of the crack by the adsorption of an atom or molecule. ${ }^{15), 16)}$

The relation between the work done on steel to create a new surface and the surface energy of the steel would be expressed as

$$
W=2 \gamma_{\text {steel }}
$$

where,

$W:$ energy required for creating new surface

$\gamma$ steel: surface energy of steel.

When the new clear surface is created in an environment, the surface energy of the steel would be reduced due to heat of adsorption which will be different for different environments.

$$
W=2 \gamma_{\text {steel-environment }}
$$

Therefore, the work done required for creating new surface in an environment would also be reduced depending on the system concerned.

Unfortunately, the heats of adsorption of the solutions on the steel employed here do not seem to be available at present. A qualitative comparison of the heats of adsorption was attempted from the point of molecular structure of those solutions.

Water which has $\mathrm{H}-\mathrm{O}-\mathrm{H}$ bonds would be the most active among the solutions. The heat of adsorption would be the largest causing the lowest $K_{\text {Isce }}$ value and most susceptible environment. The amount of $\mathrm{NaCl}$ will not change significantly the activity of water. Excess addition of $\mathrm{NaCl}$, for example $20 \%$, would decrease the activity of water and the susceptibility of delayed failure characteristics by this aqueous solution might become blunt. In other words, $K_{\text {Isce }}$ might be increased. The next most active solution would be butyl alcohol, which has $-\mathrm{OH}$ radical. The heat of adsorption would be the next following water. The third, and the least active solution would be acetone which has $>\mathrm{C}=0$ radical. The heat of adsorption on steel would be the least among the three solutions.
The results in this investigation agree well with the above tendency and the degree of the susceptibility of each solution could also be accounted for by the size of molecules of the solutions.

Decane solution which has a straight carbon chain bond of $\mathrm{C}_{10} \mathrm{H}_{22}$ was anticipated to be far less susceptible in light of the above considerations. The results of tests in a decane environment using $7.62 \mathrm{~mm}$ specimens are illustrated in Fig. 8. The curve indicates that decane actually has far less effect on delayed failure characteristics. Thus, the stress sorption cracking mechanism also appears to satisfy the experimental observations.

Further investigations would be required to define which mechanism is dominant. It might be significant to examine the existence of discontinuous crack propagation in these organic solutions. Discontinuous crack propagation can be examined by resistance measurements at relatively low temperature, and is unique characteristic of the hydrogen embrittlement mechaanism.

\section{Summary}

Delayed failure curves, as a criterion of stress corrosion cracking were examined in an environment of aqueous and organic solutions using round bar, precracked, 4340 specimens at $190 \mathrm{~kg} / \mathrm{mm}^{2}$ strength level. At these high strength levels, the steel was extremely susceptible to delayed failure in water and dilute $\mathrm{NaCl}$ aqueous solutions. Although the degree of susceptibility was less, the organic solutions (butyl alcohol and acetone) also definitely caused delayed failure in the same steel.

The $K_{\text {Isce }}$ values on the basis of fracture toughness testing were as follows :

$$
\begin{array}{lr}
K_{I c} \text { in air } & 194.9 \mathrm{~kg} \sqrt{\mathrm{mm}} / \mathrm{mm}^{2} \\
\text { Aqueous solutions } & 56.7 \mathrm{~kg} \sqrt{\mathrm{mm}} / \mathrm{mm}^{2} \\
\text { Butyl alcohol } & 92.1 \mathrm{~kg} \sqrt{\mathrm{mm} / \mathrm{mm}^{2}} \\
\text { Acetone } & 124.0 \mathrm{~kg} \sqrt{\mathrm{mm} / \mathrm{mm}^{2}} .
\end{array}
$$

The cause of delayed failure in the aqueous solutions can be attributed to hydrogen embrittlement. A stress sorption cracking mechanism appears to be consistent with the experimental observations in terms of heat of adsorption on steel.

Precracking by hydrogen embrittlement was most effective in obtaining uniform cracks at the tip of the notch, and also presented the additional advantage of minimizing localized plastic flow at the root of the crack. This, in turn, will minimize corrosion resulting from local action cells between the deformed and undeformed material.

The specimen size necessary for plane strain condition of fracture toughness tests was determined in advance. Specimen shank diameters of 7.62 and $11.43 \mathrm{~mm}$ at $190 \mathrm{~kg} / \mathrm{mm}^{2}$ strength level were appropriate and were employed in the stress corrosion delayed failure tests.

\section{REFERENCES}

1) B. F. Brown: Materials Research \& Standards, 6 (1966), 129. 
2) E. A. Steigerwald: Proc. ASTM, 60 (1960), 750.

3) E. A. Steigerwald: TRW Engineering Report, ER-6994 (December, 1966).

4) C. D. Beachem and B. F. Brown: Stress Corrosion Testing, ASTM STP 425 (1967), 31, ASTM, Pa.

5) Fracture Toughness and Its Applications, ASTM STP 381, (1965), 171, 358, ASTM, Pa.

6) W. F. Brown, Jr. and J. E. Srawley: Plane Strain Crack Toughness Testing of High Strength Metallic Materials, ASTM STP 410, (1967), ASTM, Pa.

7) A. R. Troiano: Trans. ASM, $\mathbf{5 2}$ (1960), 54.

8) Materials Research \& Standards, 2 (1962) 203.

9) R. P. Frohmberg, W. J. Barnett, and A. R. Troiano: Trans. ASM, 47 (1955), 892.

10) H. H. Johnson: Materials Research \& Standards, 5 (1965),
442.

11) E. A. Steigerwald: Plane Strain Fracture Toughness for Handbook Representation, AFML-TR-67-187, TRW, Inc., (July, 1967).

12) E. A. Steigerwald and W. D. Benjamin: TRW Engineering Report, ER-6877-6 (October, 1967).

13) E. A. Steigerwald and W. D. Benjamin: TRW Engineering Report, ER-6877-2 (October, 1966).

14) G. L. Hanna, A. R. Troiano, and E. A. Steigerwald: Trans. ASM, $\mathbf{5 7}$ (1964), 658

15) E. G. Coleman, D. Weinstein, and W. Rostoker: Acta Met., 9 (1961), 491 .

16) T. Fort, Jr.: Case WRU, Private Communication.

17) E. A. Steigerwald: TRW Materials Research Laboratory Cleveland, Ohio, Private Communication. 